\title{
BMJ Open Effect of protective ventilation on postoperative pulmonary complications in patients undergoing general anaesthesia: a meta-analysis of randomised controlled trials
}

Tianzhu Tao, Lulong Bo, Feng Chen, Qun Xie, Yun Zou, Baoji Hu, Jinbao Li, Xiaoming Deng

To cite: Tao T, Bo L, Chen F, et al. Effect of protective ventilation on postoperative pulmonary complications in patients undergoing general anaesthesia: a meta-analysis of randomised controlled trials. BMJ Open 2014;4: e005208. doi:10.1136/ bmjopen-2014-005208

- Prepublication history for this paper is available online. To view these files please visit the journal online (http://dx.doi.org/10.1136/ bmjopen-2014-005208).

TT and LB contributed equally.

Received 12 March 2014 Revised 23 May 2014 Accepted 4 June 2014

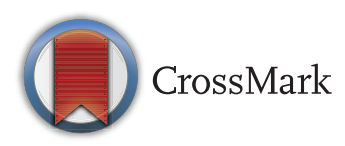

Department of Anesthesiology and Intensive Care, Changhai Hospital, Second Military Medical University, Shanghai, China

Correspondence to

Dr Jinbao Li:

lijinbaoshanghai@163.com and Dr Xiaoming Deng;

deng_x@yahoo.com

\section{ABSTRACT}

Objective: To determine whether anaesthetised patients undergoing surgery could benefit from intraoperative protective ventilation strategies.

Methods: MEDLINE, EMBASE and Cochrane Central Register of Controlled Trials (CENTRAL) were searched up to February 2014. Eligible studies evaluated protective ventilation versus conventional ventilation in anaesthetised patients without lung injury at the onset of mechanical ventilation. The primary outcome was the incidence of postoperative pulmonary complications. Included studies must report at least one of the following end points: the incidence of atelectasis or acute lung injury or pulmonary infections.

Results: Four studies (594 patients) were included. Meta-analysis using a random effects model showed a significant decrease in the incidence of atelectasis (OR=0.36; $95 \% \mathrm{Cl} 0.22$ to $0.60 ; p<0.0001 ; \mathrm{I}^{2}=0 \%$ ) and pulmonary infections $(\mathrm{OR}=0.30 ; 95 \% \mathrm{Cl} 0.14$ to 0.68 ; $p=0.004 ; I^{2}=20 \%$ ) in patients receiving protective ventilation. Ventilation with protective strategies did not reduce the incidence of acute lung injury $(\mathrm{OR}=0.40$; $95 \% \mathrm{Cl} 0.07$ to $2.15 ; p=0.28 ;\left.\right|^{2}=12 \%$ ), all-cause mortality $(\mathrm{OR}=0.77 ; 95 \% \mathrm{Cl} 0.33$ to $1.79 ; \mathrm{p}=0.54$; $\mathrm{I}^{2}=0 \%$ ), length of hospital stay (weighted mean difference $(\mathrm{WMD})=-0.52$ day, $95 \% \mathrm{Cl}-4.53$ to 3.48 day; $p=0.80 ; I^{2}=63 \%$ ) or length of intensive care unit stay (WMD $=-0.55$ day, $95 \% \mathrm{Cl}-2.19$ to 1.09 day; $\mathrm{p}=0.51 ; \mathrm{I}^{2}=39 \%$ ).

Conclusions: Intraoperative use of protective ventilation strategies has the potential to reduce the incidence of postoperative pulmonary complications in patients undergoing general anaesthesia. Prospective, well-designed clinical trials are warranted to confirm the beneficial effects of protective ventilation strategies in surgical patients.

\section{INTRODUCTION}

Postoperative pulmonary complications are the main cause of overall perioperative morbidity and mortality in patients following

\section{Strengths and limitations of this study}

- Accumulating evidence suggests that mechanical ventilation using a high tidal volume in particular may cause alveolar overstretching or even induce lung injury. Whether anaesthetised patients undergoing surgery could benefit from intraoperative protective ventilation remains unclear and controversial. We reported in this meta-analysis based on the data available that intraoperative use of protective ventilation strategies in patients undergoing general anaesthesia could reduce the incidence of postoperative complications including atelectasis and pulmonary infections. Our study involved only eligible randomised controlled trials in the combined analysis to minimise the potential biases. Hence, our study may provide the latest evidence of protective ventilation in the operating room.

- First, most of the trials enrolled in this meta-analysis did not allow differentiation between the effects of low tidal volumes and higher positive end-expiratory pressure or application of recruitment manoeuvres. Second, although no significant heterogeneity was observed in our analysis, the primary studies varied in the design, study population and follow-up periods, and so the pooled results need to be viewed cautiously. Finally, despite a comprehensive search strategy, we could not assess the publication bias due to the small number of studies involved.

general anaesthesia. ${ }^{1}{ }^{2}$ Induction of anaesthesia is consistently accompanied by a significant reduction in lung volume and rapid formation of atelectasis. ${ }^{3}$ Prevention of these complications would improve the quality of medical care and decrease hospital costs. ${ }^{4}$ However, few interventions have been identified to clearly or possibly reduce the postoperative lung function impairment. ${ }^{5}$ 
Mechanical ventilation is an essential supportive strategy in patients undergoing general anaesthesia. Knowing that a high tidal volume (VT; $10-15 \mathrm{~mL} / \mathrm{kg}$ of predicted body weight) can maintain better gas exchange and intraoperative mechanics, it has conventionally been recommended for intraoperative ventilation. ${ }^{6}$ However, accumulating evidence from experimental and clinical studies has indicated that mechanical ventilation using a high VT in particular may cause alveolar overstretching or even induce organ injury. ${ }^{78}$

A protective ventilation strategy refers to the use of low VT (in the range of $4-8 \mathrm{~mL} / \mathrm{kg}$ of the predicted body weight) with positive end-expiratory pressure (PEEP), with or without recruitment manoeuvres. Protective ventilation has been considered the optimal practice in patients suffering from the acute respiratory distress syndrome (ARDS). ${ }^{10}$ However, few human studies have assessed how to ventilate healthy lungs in patients undergoing general anaesthesia. In a large retrospective cohort study, Gajic et $a l^{11}$ found that the development of acute lung injury (ALI) was independently associated with a high VT and high peak airway pressure. Subsequently, several studies attempted to uncover the cause of ventilator-associated lung injury and find ways to minimise the side effects of high volume-high pressure ventilation in surgical patients. A prior meta-analysis of clinical trials performed by Hemmes $e t a l^{12}$ reported that intraoperative lung protective ventilator settings had the potential to protect against pulmonary complications. Their study included eight articles with 1669 patients. Of these, two large-scale studies (1320 patients) were observational and three studies were on one-lung ventilation settings. Therefore, the results of this study cannot be considered as definitive. Recently, two additional, well-designed randomised controlled trials (RCTs) were published. To better specify the effect of protective ventilation in surgical patients, excluding cardiac and thoracic surgery, we conducted the present meta-analysis of RCTs focusing on the effects of protective ventilation on the incidence of postoperative pulmonary complications.

\section{METHODS}

\section{Search strategy}

This analysis followed the recommendations of the Cochrane Handbook for Systematic Reviews of Interventions and the QUOROM (quality of reporting of meta-analyses) statement. We searched MEDLINE, EMBASE and Cochrane Central Register of Controlled Trials (CENTRAL) updates to February 2014. Our search was restricted to RCTs published in full-text versions, without a language restriction. Additional relevant articles were identified by manually searching bibliographies and conferences. Our search strategy was based on three search themes, all combined with the Boolean OR operator. The protective ventilation filter contained the following MeSH terms: 'protection ventilation', 'low tidal volume ventilation' and 'conventional ventilation'. The surgical patients filter included: 'surgical', 'surgery', 'general anesthesia' and 'operating room'. The clinical trials filter included the MeSH terms 'clinical trials (publication type)', 'clinical trials as topic' with text words 'trial*' or 'random*'.

\section{Selection criteria}

Study inclusion criteria were based on the following attributes: (1) population: adult (>18 years) surgical patients receiving mechanical ventilation in the operating room; (2) intervention: the use of a protective ventilation strategy (lower VT with PEEP, with or without recruitment manoeuvres) versus the conventional ventilation method (high VT, with or without PEEP and recruitment manoeuvres), cardiac surgery and one-lung ventilation studies was excluded; (3) predefined outcomes: the incidence of atelectasis, ALI, pulmonary infections, short-term postoperative mortality ( $<60$ days), length of hospital and intensive care unit (ICU) stay, $\mathrm{paCO}_{2}$ and/or plateau pressure and (4) design: randomised controlled parallel trials. Eligible studies must report at least one of the following end points: the incidence of atelectasis or ALI or pulmonary infections.

\section{Data extraction and validity assessment}

Three authors screened the titles and abstracts of initial search results, extracted the data and assessed the risk of bias independently. Any disagreements between the reviewers were resolved by discussion. Additional information was obtained by directly questioning the correspondence authors in relevant articles whenever needed.

Methodological quality was assessed using the Cochrane Collaboration risk of bias tool that considered seven different domains: adequacy of sequence generation, allocation concealment, blinding of participants, blinding for outcome assessment, incomplete outcome data, selective outcome reporting and other potential sources of bias.

\section{Statistical analysis}

We extracted data regarding the study design, patient population, interventions and parallel controls, intraoperative ventilation mechanics and clinical outcomes. The primary end points concerned were the incidence of atelectasis, ALI and pulmonary infections. The secondary outcomes included all-cause mortality and length of ICU and hospital stay. Some trials reported median as a treatment effect, with the accompanying IQR or range. For the purpose of analysis, the median was assumed to be equivalent to the mean, and SD was estimated with $\mathrm{IQR} / 1.35$ or range/4 according to the sample size and distribution (Cochrane Handbook). For dichotomous data, OR was used to describe the size of treatment effect, and for continuous variables, weighted mean difference (WMD) was employed.

Homogeneity assumption was measured by $\mathrm{I}^{2}$. It is calculated as $\mathrm{I}^{2}=100 \% \times(\mathrm{Q}-\mathrm{df}) / \mathrm{Q}$, where $\mathrm{Q}$ is Cochran's 
heterogeneity statistic. ${ }^{13}$ A value of $0 \%$ indicates no observed heterogeneity, and larger values correlated with the increasing heterogeneity.

Synthesis of the data was performed using the random effects model. Funnel plots of the incidence of atelectasis were used to visually assess the publication bias. Sensitivity analyses were carried out for different subgroups according to relevant clinical features.

All analyses were performed using Review Manager (RevMan) (Computer program) V.5.1. Significant differences are set at $\mathrm{p}<0.05$.

\section{RESULTS}

\section{Literature identification and study characteristics}

Our initial search yielded 1447 publications (547 from MEDLINE, 480 from EMBASE and 420 from CENTRAL). After removing 307 duplicates, abstracts of 1140 articles were screened by three independent authors. Of these, 58 records were retrieved for detailed evaluation. Subsequently, 50 articles were excluded for the following reasons: no data on outcomes of interest, observational cohort study, not for treatment of surgical patients, cardiac or one-lung ventilation, etc. The remaining four RCTs enrolling 594 patients were included in the final analysis (figure 1).

Table 1 describes the characteristics of the four studies including patient enrolment, surgical type, duration of ventilation, ventilation settings and primary outcomes. All these studies were conducted on abdominal surgical patients with one study focusing on the elderly population (40 patients, age $>65$ ). VT was set to $6-8 \mathrm{~mL} / \mathrm{kg}$ of the predicted body weight in the protective group and $9-12 \mathrm{~mL} / \mathrm{kg}$ in the control group. Three studies used PEEP (4-12 $\mathrm{cm} \mathrm{H}_{2} \mathrm{O}$ ) only in the treatment group and one study ${ }^{14}$ used PEEP $\left(5 \mathrm{~cm} \mathrm{H}_{2} \mathrm{O}\right)$ in both groups. The recruitment manoeuvre was performed in the protective group in all included studies. ${ }^{14-17}$ The chest radiograph (X-rays) was used in all studies to detect atelectasis. Lung injury was diagnosed according to the AmericanEuropean Consensus Conference definition in three studies, ${ }^{14} 1517$ with no specific report in one study. ${ }^{16}$

An overview of the risk of bias is described in figure 2 . All these studies reported adequate methods of sequence generation and allocation concealment. Double-blinded fashion was performed in two studies $^{14} 17$ while the other two studies were open labelled. Age, weight, gender and duration of ventilation were comparable in parallel. Plateau pressure tended to be lower in the protective ventilation group compared with that in the control group in the final follow-up, but the difference did not reach statistical significance $\left(\mathrm{WMD}=-0.63 \mathrm{~cm} \mathrm{H}_{2} \mathrm{O}, 95 \%\right.$ CI -1.85 to $-0.58, \mathrm{p}=0.31$ ).

\section{Primary outcome}

All studies reported the incidence of atelectasis during follow-up periods. Atelectasis developed in 53 of the 297 patients ventilated with protective strategies and 88 of the

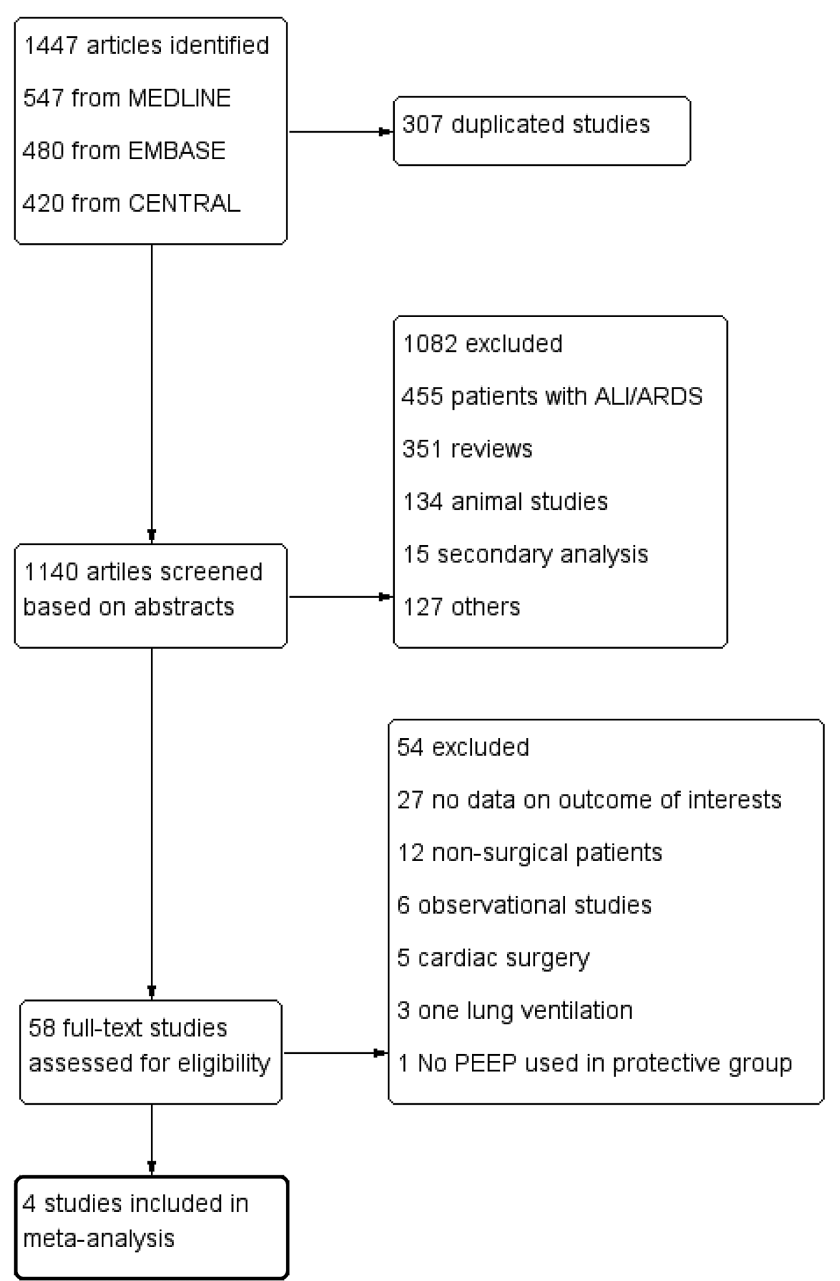

Figure 1 Literature search strategy. ALI, acute lung injury; ARDS, acute respiratory distress syndrome; CENTRAL, Cochrane Central Register of Controlled Trials; PEEP, positive end-expiratory pressure.

297 patients ventilated with conventional VTs. Our meta-analysis of these trials indicated that there was a significant decrease in the incidence of atelectasis in those using the protective ventilation strategy $(\mathrm{OR}=0.36 ; 95 \% \mathrm{CI}$ 0.22 to $0.60 ; \mathrm{p}<0.0001 ; \mathrm{p}$ for heterogeneity $=0.75, \mathrm{I}^{2}=0 \%$; figure 3). The incidence of pulmonary infections was lower in the protective ventilation group compared with the conventional ventilation group $(\mathrm{OR}=0.30 ; 95 \% \mathrm{CI} 0.14$ to $0.68 ; \mathrm{p}=0.004 ; \mathrm{p}$ for heterogeneity $=0.29, \quad \mathrm{I}^{2}=20 \%$; figure 4). Protective ventilation was associated with decreased incidence of ALI, but the difference did not reach statistical significance $(\mathrm{OR}=0.40 ; 95 \%$ CI 0.07 to 2.15; $\mathrm{p}=0.28$; $\mathrm{p}$ for heterogeneity $=0.32, \mathrm{I}^{2}=12 \%$; figure 5 ).

\section{Secondary outcomes}

Data from three studies were available for assessing mortality during the follow-up periods. For the 541 evaluable patients, no significant reduction in the risk of mortality was observed in patients receiving protective ventilation strategies $(\mathrm{OR}=0.77 ; 95 \%$ CI 0.33 to $1.79 ; \mathrm{p}=0.54$; $\mathrm{p}$ for heterogeneity $=0.91, \mathrm{I}^{2}=0 \%$ ). Length of hospital or ICU 


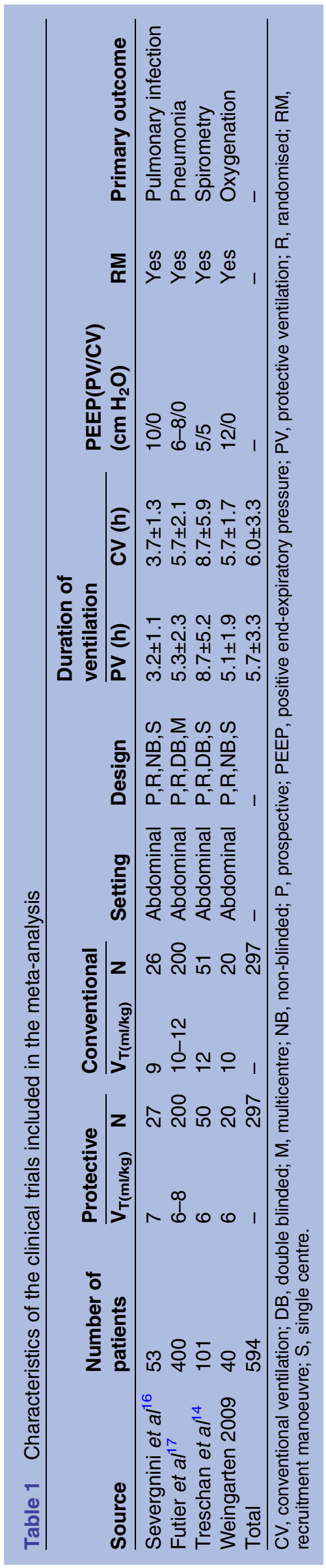

stay was not significantly different in the protective ventilation group compared with the control group (WMD= -0.52 day, $95 \%$ CI -4.53 to 3.48 day, $p=0.80$, $p$ for heterogeneity $=0.07, \quad \mathrm{I}^{2}=63 \%$; $\mathrm{WMD}=-0.55$ day, $95 \%$ CI -2.19 to 1.09 day, $\mathrm{p}=0.51, \mathrm{p}$ for heterogeneity $=0.20$, $\mathrm{I}^{2}=39 \%$; respectively).

\section{Sensitivity analysis}

Stratified analysis was performed based on a number of key study characteristics. Three studies incorporated PEEP and recruitment manoeuvres in the protective ventilation group versus no PEEP or recruitment manoeuvres in the control group. In one study, ${ }^{6}$ both groups received the same PEEP and recruitment manoeuvres. Excluding this study did not change the results of any primary outcomes. Weingarten et al $\mathrm{l}^{15}$ investigated 40 elderly patients undergoing abdominal surgery. Exclusion of this trial did not change the results. Regarding the incidence of atelectasis, no significant difference was found when excluding the largest study by Futier et $^{a l .}{ }^{17}$

\section{DISCUSSION}

The main finding of this meta-analysis is that protective ventilation strategies can reduce the incidence of atelectasis and pulmonary infections in surgical patients at the onset of ventilation. Protective ventilation strategies did not reduce the incidence of ALI, all-cause mortality or length of hospital or ICU stay.

The prescription of mechanical ventilation has changed over the past few decades, with low VTs strongly advocated, especially in patients with ALI. ${ }^{9} 18$ Basic and clinical evidence indicated that an injurious ventilation setting could result in the development of diffuse alveolar damage, pulmonary oedema, recruitment of inflammatory cells and production of cytokines. ${ }^{19}{ }^{20}$ It is evident that the use of low VTs is associated with reduced morbidity and mortality in patients with ARDS, and thus guidelines strongly advise using protective ventilation strategies in these patients. ${ }^{21-23}$ However, there is little evidence regarding the benefits of ventilation with low VTs in patients undergoing surgery without ARDS preoperatively. In order to prevent atelectasis and hypoxaemia in surgical patients, it is still common today for surgical patients undergoing general anaesthesia to receive a larger VT. ${ }^{24}{ }^{25}$ Later animal studies indicated that ventilation with a higher VT could damage the healthy lungs, stimulate the release of inflammatory chemicals and predispose animals to organ damage. ${ }^{26-28}$ However, some observational studies in humans have argued the usefulness of ventilation with a low VT. ${ }^{29} 30$ Recently, several clinical trials were conducted in the operating room to study the influence of ventilator settings on the surrogate end points, including inflammatory responses, postoperative pulmonary complications, postoperative lung function and oxygenation. Despite the heterogeneity of surgical types, most trials found 
Figure 2 Overall risk of bias using the Cochrane risk of bias tool.

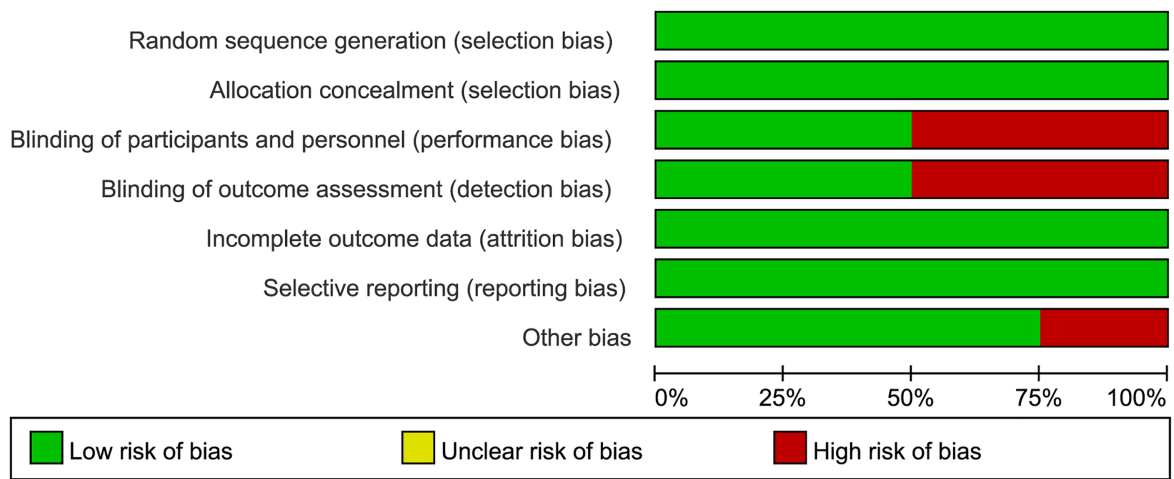

Random sequence generation (selection bias)

Allocation concealment (selection bias)

Blinding of participants and personnel (performance bias)

Blinding of outcome assessment (detection bias)

complete outcome data (attrition bias)

Selective reporting (reporting bias)

Other bias

High risk of bias that protective ventilation strategies could attenuate the inflammatory responses, improve lung function and minimise potential oxygen desaturation. ${ }^{16}$ 31-35

Our aim was to combine data from all well-designed RCTs available that had the scope to show the effects of protective ventilation in surgical patients. The current meta-analysis focused mainly on the clinical outcomes with protective ventilation. Cardiac or thoracic surgery studies were excluded to minimise the heterogeneity. The results of our meta-analysis are mainly in line with a previous systematic review suggesting that protective ventilation significantly reduced the incidence of postoperative pulmonary complications. ${ }^{12}$ However, we did not find a significantly decreased incidence of ALI in the protective ventilation group. The difference can be explained by the fact that we excluded the observational studies in this meta-analysis and involved two further RCTs, which were not analysed in the prior study. Furthermore, we excluded one-lung ventilation studies to provide a more definitive analysis. Hence, our study may provide more valid evidence and minimise potential bias.

It seems rational to draw a conclusion that lower VTs can decrease the intrapulmonary pressure and reduce the risk of ventilation-associated lung injury. However, we could not exclude the possibility that it may increase the cyclic alveolar collapse of dependent lung regions, thus raising the risk of atelectasis and hypercapnia. ${ }^{36} 37$ Application of PEEP and recruitment manoeuvres may counteract these side effects of low VT ventilation. The use of moderate levels of PEEP was effective to maintain the end-expiratory lung volume and improve the oxygenation and dynamic compliance of the respiratory system. ${ }^{38}$ Although the optimal level of PEEP is undetermined, it has been repeatedly shown that the application of zero PEEP was associated with increased hypoxaemia and infections. ${ }^{39}{ }^{40}$ We speculate that PEEP may contribute to the beneficial effect of protective ventilation and could be an indispensable component. Therefore, we defined protective ventilation as low VT with PEEP and excluded the study $^{41}$ which applied low VT without PEEP in the experimental group. Treschan et $a l^{14}$ used a minimum of $5 \mathrm{~cm} \mathrm{H}_{2} \mathrm{O}$ PEEP in both groups to counterbalance the component of cyclic of airway opening and closing. Interestingly, their study found that ventilation with lower VTs during upper abdominal surgery did not improve the postoperative lung function. However, their results should be interpreted cautiously because a significantly higher minute ventilation and twofold higher respiration rate were used in the low VT group (7.8 \pm 2.1 vs $6.2 \pm 1.9 \mathrm{~L} / \mathrm{min} ; 17 \pm 4$ vs $8 \pm 4$ times/min, respectively).

Three clinical trials in this meta-analysis used recruitment manoeuvres in the protective ventilation group versus no recruitment manoeuvres in the control group. Pooled analyses of these trials indicate that protective ventilation with recruitment manoeuvres led to a lower incidence of atelectasis and pulmonary infections versus conventional ventilation without recruitment manoeuvres. Thinking PEEP alone cannot effectively reopen the collapsed lungs; one may argue that a repeated recruitment manoeuvre is an essential component of protective ventilation for the complete reopening

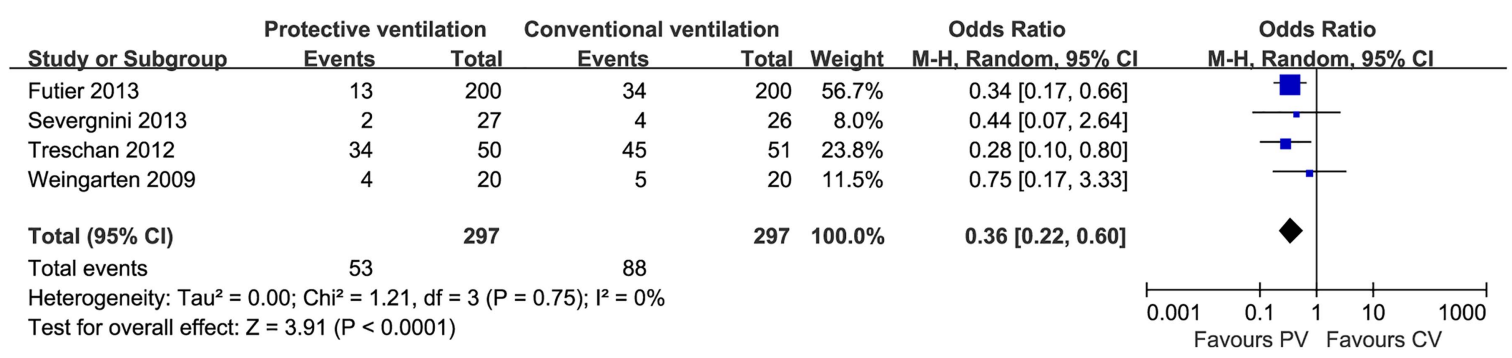

Figure 3 Forest plot for the incidence of atelectasis. A pooled OR was calculated using the random effects model according to the Mantel-Haenszel $(\mathrm{M}-\mathrm{H})$ method. The incidence of atelectasis was significantly lower in the PV group. CV, conventional ventilation; $\mathrm{PV}$, protective ventilation. 


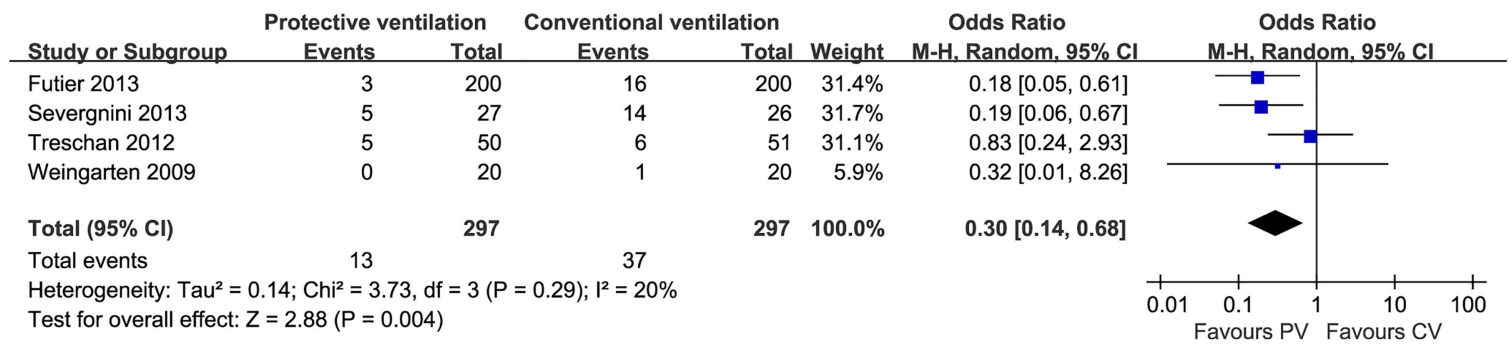

Figure 4 Forest plot for the incidence of pulmonary infections. A pooled OR was calculated using the random effects model according to the Mantel-Haenszel (M-H) method. The incidence of pulmonary infections was significantly lower in the PV group. $\mathrm{CV}$, conventional ventilation; $\mathrm{PV}$, protective ventilation.

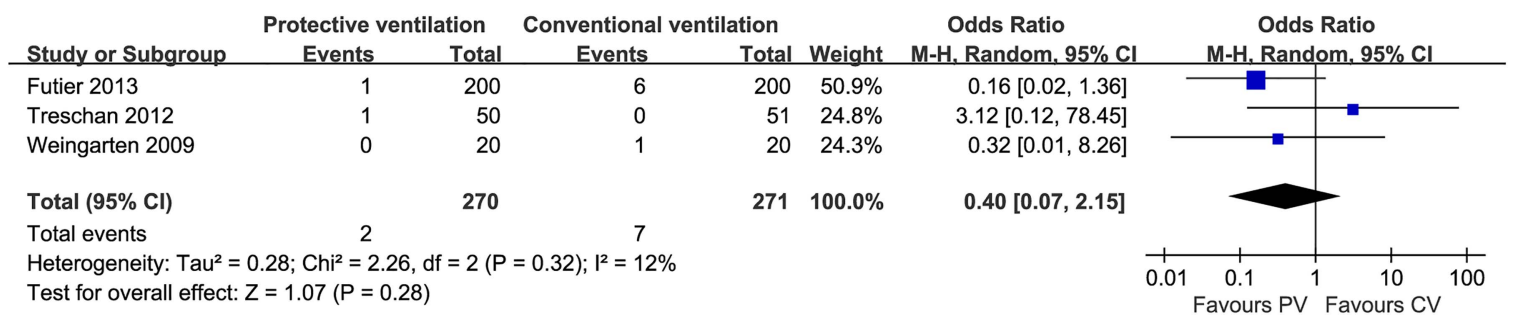

Figure 5 Forest plot for the incidence of acute lung injury (ALI). A pooled OR was calculated using the random effects model according to the Mantel-Haenszel $(\mathrm{M}-\mathrm{H})$ method. Protective ventilation was associated with decreased incidence of ALI, but the difference did not reach statistical significance. CV, conventional ventilation; PV, protective ventilation.

of atelectasis. Serita $e t a t^{42}$ found that individualised recruitment manoeuvres brought about an improvement in oxygenation and lung compliance in patients undergoing selective cardiac surgery. The beneficial effects of recruitment manoeuvres were also demonstrated in obese patients during laparoscopic surgery, ${ }^{43}$ while these effects in other types of surgery need to be clarified. It should be noted that recruitment manoeuvres could cause a decrease in the right ventricular preload and a reduction in the left ventricular stroke volume, which should be used cautiously in haemodynamically unstable patients. Given the uncertain influence of recruitment manoeuvres on clinical outcomes, it is prudent to neither recommend nor reject recruitment manoeuvres as a routine at present.

There are several limitations in the current study. First, the present study included only four clinical trials due to the more restricted selection criteria. Publication bias could not be assessed owing to the small number of studies. Second, all the trials enrolled in this meta-analysis applied lower VTs, higher PEEP and recruitment manoeuvres in the protective ventilation group; it seems impossible to simply attribute the beneficial effects to just one of these components. In fact, PEEP and recruitment manoeuvres could be helpful to overcome the potential effects of low VT ventilation on oxygenation. It would be reasonable to use these methods in combination. To address the issue of which one is more closely related to a lower incidence of postoperative complications, further studies are still warranted. Finally, although no significant heterogeneity was observed in our analysis, the primary studies varied in the design, study population and follow-up periods, and the pooled results need to be viewed cautiously.

\section{CONCLUSION}

Intraoperative use of protective ventilation strategies in patients undergoing general anaesthesia could reduce the incidence of postoperative atelectasis and pulmonary infections. Prospective, well-designed clinical trials are warranted to confirm the beneficial effect of protective ventilation strategies in surgical patients, especially in those with a high risk of lung morbidity.

Acknowledgements The authors would like to thank the authors of primary studies.

Contributors TT and LB contributed equally to this article. They participated in the study design and data collection and also drafted the manuscript. FC, $\mathrm{QX}, \mathrm{YZ}$ and $\mathrm{BH}$ helped in the design of the study and analysed the data. $\mathrm{XD}$ and $\mathrm{JL}$ designed this study, supervised the data collection and revised this article. All authors read and approved the final manuscript.

Funding This work was supported by the research grant from the National Natural Science Foundation of China (Grant No.81272065).

\section{Competing interests None.}

Provenance and peer review Not commissioned; externally peer reviewed.

Data sharing statement The statistical code and data set are available from the corresponding authors ( $\mathrm{JL}$ and $\mathrm{XD}$ ), who will provide a permanent, citable and open access home for the data set.

Open Access This is an Open Access article distributed in accordance with the Creative Commons Attribution Non Commercial (CC BY-NC 4.0) license, which permits others to distribute, remix, adapt, build upon this work noncommercially, and license their derivative works on different terms, provided 
the original work is properly cited and the use is non-commercial. See: http:// creativecommons.org/licenses/by-nc/4.0/

\section{REFERENCES}

1. Khuri SF, Henderson WG, DePalma RG, et al. Determinants of long-term survival after major surgery and the adverse effect of postoperative complications. Ann Surg 2005;242:326-41; discussion 341-323.

2. Arozullah AM, Khuri SF, Henderson WG, et al. Development and validation of a multifactorial risk index for predicting postoperative pneumonia after major noncardiac surgery. Ann Intern Med 2001;135:847-57.

3. Hedenstierna G, Edmark L. The effects of anesthesia and muscle paralysis on the respiratory system. Intensive Care Med 2005;31:1327-35

4. Shander A, Fleisher LA, Barie PS, et al. Clinical and economic burden of postoperative pulmonary complications: patient safety summit on definition, risk-reducing interventions, and preventive strategies. Crit Care Med 2011;39:2163-72.

5. Lawrence VA, Cornell JE, Smetana GW. Strategies to reduce postoperative pulmonary complications after noncardiothoracic surgery: systematic review for the American College of Physicians. Ann Intern Med 2006;144:596-608.

6. Bendixen $\mathrm{HH}$, Hedley-Whyte J, Laver MB. Impaired oxygenation in surgical patients during general anesthesia with controlled ventilation. A concept of atelectasis. N Engl J Med 1963;269:991-6

7. Imai $\mathrm{Y}$, Parodo J, Kajikawa $\mathrm{O}$, et al. Injurious mechanical ventilation and end-organ epithelial cell apoptosis and organ dysfunction in an experimental model of acute respiratory distress syndrome. JAMA 2003;289:2104-12

8. Lellouche F, Dionne S, Simard S, et al. High tidal volumes in mechanically ventilated patients increase organ dysfunction after cardiac surgery. Anesthesiology 2012;116:1072-82.

9. Ventilation with lower tidal volumes as compared with traditional tida volumes for acute lung injury and the acute respiratory distress syndrome. The Acute Respiratory Distress Syndrome Network N Engl J Med 2000;342:1301-8.

10. Petrucci $\mathrm{N}$, lacovelli $\mathrm{W}$. Lung protective ventilation strategy for the acute respiratory distress syndrome. Cochrane Database Syst Rev 2007;(3):CD003844.

11. Gajic O, Dara SI, Mendez JL, et al. Ventilator-associated lung injury in patients without acute lung injury at the onset of mechanical ventilation. Crit Care Med 2004;32:1817-24.

12. Hemmes SN, Serpa Neto A, Schultz MJ. Intraoperative ventilatory strategies to prevent postoperative pulmonary complications: a meta-analysis. Curr Opin Anaesthesiol 2013;26:126-33.

13. Higgins JP, Thompson SG, Deeks JJ, et al. Measuring inconsistency in meta-analyses. BMJ 2003;327:557-60.

14. Treschan TA, Kaisers W, Schaefer MS, et al. Ventilation with low tidal volumes during upper abdominal surgery does not improve postoperative lung function. Br J Anaesth 2012;109:263-71.

15. Weingarten TN, Whalen FX, Warner DO, et al. Comparison of two ventilatory strategies in elderly patients undergoing major abdominal surgery. Br J Anaesth 2010;104:16-22.

16. Severgnini $P$, Selmo G, Lanza $C$, et al. Protective mechanical ventilation during general anesthesia for open abdominal surgery improves postoperative pulmonary function. Anesthesiology 2013;118:1307-21.

17. Futier E, Constantin JM, Paugam-Burtz C, et al. A trial of intraoperative low-tidal-volume ventilation in abdominal surgery. N Engl J Med 2013;369:428-37

18. Sakr Y, Vincent JL, Reinhart K, et al. High tidal volume and positive fluid balance are associated with worse outcome in acute lung injury. Chest 2005;128:3098-108.

19. Dreyfuss D, Saumon G. Ventilator-induced lung injury: lessons from experimental studies. Am J Respir Crit Care Med 1998;157:294-323.

20. Plataki M, Hubmayr RD. The physical basis of ventilator-induced lung injury. Expert Rev Respir Med 2010;4:373-85.

21. Hager DN, Krishnan JA, Hayden DL, et al. Tidal volume reduction in patients with acute lung injury when plateau pressures are not high. Am J Respir Crit Care Med 2005;172:1241-5.
22. George N. Protective ventilation of patients with ARDS. Br J Anaesth 2004;92:906; author reply 906-907.

23. Dellinger RP, Levy MM, Carlet JM, et al. Surviving Sepsis Campaign: international guidelines for management of severe sepsis and septic shock: 2008. Crit Care Med 2008;36:296-327.

24. Wrigge $\mathrm{H}$, Pelosi $\mathrm{P}$. Tidal volume in patients with normal lungs during general anesthesia: lower the better? Anesthesiology 2011;114:1011-13.

25. Blum JM, Fetterman DM, Park PK, et al. A description of intraoperative ventilator management and ventilation strategies in hypoxic patients. Anesth Analg 2010;110:1616-22.

26. Tremblay L, Valenza F, Ribeiro SP, et al. Injurious ventilatory strategies increase cytokines and c-fos m-RNA expression in an isolated rat lung model. J Clin Invest 1997;99:944-52.

27. Gurkan OU, O'Donnell C, Brower R, et al. Differential effects of mechanical ventilatory strategy on lung injury and systemic organ inflammation in mice. Am J Physiol Lung Cell Mol Physiol 2003;285: L710-18.

28. Dreyfuss D, Soler P, Basset G, et al. High inflation pressure pulmonary edema. Respective effects of high airway pressure, high tidal volume, and positive end-expiratory pressure. Am Rev Respir Dis 1988;137:1159-64.

29. Fernandez-Perez ER, Keegan MT, Brown DR, et al. Intraoperative tidal volume as a risk factor for respiratory failure after pneumonectomy. Anesthesiology 2006;105:14-18.

30. Fernandez-Perez ER, Sprung J, Afessa B, et al. Intraoperative ventilator settings and acute lung injury after elective surgery: a nested case control study. Thorax 2009;64:121-7.

31. Michelet $P, D$ 'Journo XB, Roch $A$, et al. Protective ventilation influences systemic inflammation after esophagectomy: a randomized controlled study. Anesthesiology 2006;105:911-19.

32. Lin WQ, Lu XY, Cao LH, et al. Effects of the lung protective ventilatory strategy on proinflammatory cytokine release during one-lung ventilation. Ai Zheng 2008;27:870-3.

33. Yang M, Ahn HJ, Kim K, et al. Does a protective ventilation strategy reduce the risk of pulmonary complications after lung cancer surgery?: a randomized controlled trial. Chest 2011;139:530-7.

34. Koner $\mathrm{O}$, Celebi $\mathrm{S}$, Balci $\mathrm{H}$, et al. Effects of protective and conventional mechanical ventilation on pulmonary function and systemic cytokine release after cardiopulmonary bypass. Intensive Care Med 2004;30:620-6.

35. Zupancich E, Paparella D, Turani F, et al. Mechanical ventilation affects inflammatory mediators in patients undergoing cardiopulmonary bypass for cardiac surgery: a randomized clinical trial. J Thorac Cardiovasc Surg 2005;130:378-83.

36. Hong CM, Xu DZ, Lu Q, et al. Low tidal volume and high positive end-expiratory pressure mechanical ventilation results in increased inflammation and ventilator-associated lung injury in normal lungs. Anesth Analg 2010;110:1652-60.

37. Wrigge $\mathrm{H}$, Uhlig $\mathrm{U}$, Zinserling J, et al. The effects of different ventilatory settings on pulmonary and systemic inflammatory responses during major surgery. Anesth Analg 2004;98:775-81, table of contents.

38. Scohy TV, Bikker IG, Hofland J, et al. Alveolar recruitment strategy and PEEP improve oxygenation, dynamic compliance of respiratory system and end-expiratory lung volume in pediatric patients undergoing cardiac surgery for congenital heart disease. Paediatr Anaesth 2009;19:1207-12.

39. Aldenkortt M, Lysakowski C, Elia N, et al. Ventilation strategies in obese patients undergoing surgery: a quantitative systematic review and meta-analysis. Br J Anaesth 2012;109:493-502.

40. Lellouche F, Lipes J. Prophylactic protective ventilation: lower tidal volumes for all critically ill patients? Intensive Care Med 2013;39:6-15

41. Cai $\mathrm{H}$, Gong $\mathrm{H}$, Zhang $\mathrm{L}$, et al. Effect of low tidal volume ventilation on atelectasis in patients during general anesthesia: a computed tomographic scan. J Clin Anesth 2007;19:125-9.

42. Serita R, Morisaki $\mathrm{H}$, Takeda J. An individualized recruitment maneuver for mechanically ventilated patients after cardiac surgery. $J$ Anesth 2009;23:87-92.

43. Futier E, Constantin JM, Pelosi $\mathrm{P}$, et al. Intraoperative recruitment maneuver reverses detrimental pneumoperitoneum-induced respiratory effects in healthy weight and obese patients undergoing laparoscopy. Anesthesiology 2010;113:1310-19. 